\title{
THE NEGOTIATION AND RESOLUTION OF THE CONFLICT IN SOUTH AFRICA: THE AHP*
}

\author{
Prof Thomas L Saaty \\ University of Pittsburgh, Pennsylvania, USA
}

\section{INTRODUCTION}

The theory of retributive conflict resolution with regard to the problem in South Africa is illustrated in this article. It is assumed that there are only two parties in the conflict: the Blacks and the Whites. A set of feasible concessions is derived for both sides to solve the problem over the short, medium and long term. The decision model of the negotiator in both cases is discussed and tables are included. It was found from this preliminary exercise that it is possible to derive an equitable solution according to the demands being made by both sides. A major limitation has been the use which had to be made of surmised hierarchies and judgements gleaned from available literature. It would be preferable were the parties to the conflict to do this themselves.

The analysis of this paper is concerned with a negotiated solution of the conflict in South Africa with the aid of a mediator, if necessary.

\section{THE ART OF NEGOTIATION}

According to Nierenberg, negotiating today is one of the least understood arts in human affairs. ${ }^{1)}$ However, in a successful negotiation everybody wins. ${ }^{2)}$

This analysis proceeds from the assumption that to negotiate a conflict there must be both common interests and issues,3) and that the moment is propitious for negotiation 
when both sides perceive that they may be better off with an agreement than without one.4) This approach uses the computer to evaluate benefit to cost ratios of concessions and seek nearly equivalent ratios for the two sides. The known principle of negotiation and conflict resolution is followed, namely that "Conflict resolution may be defined as the search for an outcome which represents to some participants an improvement from, and for no participants a worsening of, their present situation."5) Another well-known principle of negotiation is that there must be willingness to compromise and both sides must make concessions. ${ }^{61}$

The analysis of benefit to cost ratios is thus designed to yield comparable advantage to both sides. In terms of bargaining over position the participants may be expected to be relatively disciplined problem-solvers, and the goal to be a "wise" outcome for both sides. It should be reached efficiently and amicably in a way open to reason and focusing on interests and not positions, with the opportunity to invent multiple options for mutual gain, using objective criteria and attempting to reach a result based on standards independent from will.7)

The most positive way of bringing about negotiations is to hold out to the other party thg possibilities of creative solutions. ${ }^{8)}$ This is what this procedure, the Analytical Hierarchy Process, does by offering the parties a framework for developing their positions according to their knowledge and perception of the situation and providing their judgements to reach an overall assessment of their position before they embark on making offers and considering counter-offers. They would list and understand the stakes and interests of each side and be aware of the effective elements in both parties' viewpoints of the situation and of the emotional component of the other party. The process is in conformity with the findings of Axelrod,9) namely that the pay-offs of the parties need not be comparable at all, do not have to be symmetric and do not have to be measured on an absolute scale, but only relative to each other.

Conflicts are hard to negotiate because they are multiobjective, multicriteria, and multiparty, and involve intangible goals, criteria and alternatives. Conflict resolution cannot be reasoned one factor at a time and then implemented by putting the pieces together. Any action in one sphere affects perceptions in all other spheres. The usual method of logical reasoning generates linear chains of syllogisms. It is better suited for simple problems which deal with one factor at a time. What is needed is a process that can accommodate the actual complexity of a conflict situation. It is also important to be able to incorporate diverse judgements from one or several parties and test their effect on the outcome through sensitivity analysis. Often the reason a solution is 
acceptable to one side but not to the other is because no collaborative reasoning can be adequately factored into the solution. It has been found that our approach can indeed gain the participation of negotiators, diplomats and politicians. They are the people we are trying to help with our models in the first place.

The approach should also be descriptive rather than normative because the latter legislates an intellectual solution for a messy situation, resulting in disagreement and ambiguity about what comprises a solution. The Analytical Hierarchy Process with its Expert Choice ${ }^{10}$ ) software package is a psychophysical theory of ratio-scale measurement of intangibles that is well-suited for this purpose and has been applied to current conflict situations such as South Africa, the Malvinas (Falklands), Canadian-US Free Trade Negotiations, the Punjab in India, and the conflict in Northern Ireland. The AHP has been applied in several published works 11) to make trade-offs among intangibles in nuclear arms reduction negotiations between the USA and the USSR.

This paper combines the AHP approach for measuring intangibles with the idea of retributive conflicts where benefits and costs of possible concessions are estimated and used to arrive at a resolution fair to both parties.

\section{TYPES OF CONFLICT RESOLUTION}

There are two types of conflict resolution. The first kind is constructive. It is what is conventionally treated in the so-called rational approach to conflict resolution in which a party attempts to maximize its gains.

The other kind of conflict resolution is termed retributive. It involves considerations of both gains and losses to both parties. The idea is particularly relevant in long drawn-out conflicts which in the end fester and create almost inerradicable resentments. Here a party may be willing to give up much of its demands if misfortune can be brought to its opponent through some means, including justice as dispensed by the court systems. In negotiations, therefore, each party not only calculates the incremental benefits it gets, but also the costs to its opponent. The more of either, the greater the gain.

Because of space limitations, the full-blown analysis of the conflict had to be condensed and will be made available to the interested reader by the author on request. 
Gain is the product of the benefits to the party (whose aim may also be long run benefits) and the costs to the opponent. Each side must calculate its estimate of the opponent's gain (as a product of benefits to the opponent and costs to itself). It must also ensure that the ratio of its gain to the opponent's gain, which it considers as a loss, is greater than or close to unity or not less than what the opponent is perceived to get. Thus each party is concerned with maximizing its gains via its benefits and the costs to the opponent and also by negotiating to increase this gain and decrease its loss (which is the gain to the opponent). When several concessions are considered simultaneously, sums of the products of benefits and costs must be taken. The ratios for the two parties $\mathrm{A}$ and $\mathrm{B}$ are as follows:

$$
\begin{aligned}
\text { A's ratio } & =\frac{\text { Gain to A }}{A^{\prime} \text { s percept ion of Gain to } B} \\
& =\frac{S u m\left(A^{\prime} s \text { benefits } \times B^{\prime} s \text { costs }\right)}{\text { Sum (B's benefits } \left.\times A^{\prime} s \text { costs }\right)}
\end{aligned}
$$

(as perceived by A where Sum = sum taken over all concessions by B in the numerator and by $A$ in the denominator)

$$
=\frac{\text { Gain to } \mathrm{A}}{\text { Loss to } \mathrm{A}}
$$

A's perceived ratio for $B$ is the reciprocal of the above.

$$
\begin{aligned}
\text { B's ratio } & =\frac{\text { Gain to B }}{B^{\prime} \text { s percept ion of Gain to } A} \\
& =\frac{S u m\left(B^{\prime} s \text { benefits } \times A^{\prime} s\right. \text { costs) }}{\text { Sum (A's benefits } \times B^{\prime} s \text { costs) }}
\end{aligned}
$$

(as perceived by $\mathrm{B}$ where Sum = sum taken over all concessions by $\mathrm{A}$ in the numerator and by $\mathrm{B}$ in the denominator)

$$
=\frac{\text { Gain to } B}{\text { Loss to } B}
$$

B's perceived ratio for $A$ is the reciprocal of the above.

If each of the ratios is perceived by the corresponding party to be less than unity, the problem is to alter these perceptions or to increase the concessions so that both parties see that they are equally treated. 
Note that constructive conflict resolution is a special case of this whereby the costs to the opponent are assigned a unit value. Each party assumes that the opponent is paying the full cost and concentrates on maximizing its own benefits. It cannot incur any further costs on the opponent.

In many instances where the parties feel that an essential part of the conflict arises from their disparity in relative power, it would be appropriate to weight the ratio of each party by its proportion of perceived power computed for both from appropriate hierarchies of influence, as has been done in many examples. In that case, to equalize the two expressions becomes a more difficult task. By accepting guaranteed concessions, the weaker party may become stronger and its perceived power may change accordingly. It is exactly because of such possible changes that some long-standing conflicts should not be negotiated as a one-shot affair, but dealt with in terms of short-, medium- and long-range objectives.

\section{OUTLINE OF THE PROCESS}

The object is to develop a ratio of gains to losses for each party and indicate how they can be used to trade off concessions, one against one, several against one or several against several.

The concessions given below for the Whites and the Blacks in the South African conflict are not described in detail.

Although there are only two parties, Whites and Blacks, in this brief presentation, the subject has been studied by including all the factions for each of the parties. Exhibit 1 in the next section gives the concessions of the two parties in the South African conflict.

Each party needs four hierarchies to estimate benefits and costs. The first is for its actual benefits from the concessions received, the second for the costs of the concessions made, the third for its estimate of the benefits to the opponent of the concessions it makes, and the fourth for its estimate of the costs of the concessions offered by the opponent. All in all there are thus eight such hierarchies for the two parties. Only one will be illustrated in Exhibit 2 and the discussion which follows it. 
Two tables for the estimated benefits and costs for each party for each concession.are then given. Ratios of gains to losses are also shown.

A table matching single concessions from each side according to their value to each is shown. The criterion is that neither should believe that he is getting less than the other believes he is getting.

Another table can be constructed matching sets of multiple concessions of one side with those of the other, for all possible combinations which satisfy the foregoing criterion. This is not given here.

A mediator can develop his version of the eight hierarchies of the two opponents according to how he believes they will each evaluate the outcome from information he gets from them. He has four additional hierarchies for his own version of benefits and costs using actual judgements elicited when possible from the two parties or inferred from information they give him on the side. He uses these four hierarchies to propose modifications in their position towards a better solution.

A computer program is available for matching concessions. It takes a substantial amount of time to develop the mediator's proposals.

\section{APPLICATION TO THE CONFLICT IN SOUTH AFRICA}

In this section the method is set out by means of which gains involving intangible factors are calculated.

\subsection{EXHIBIT 1}

\subsubsection{Concessions by the White Government}

(1) Release "political" prisoners:

(a) all prisoners, or

(b) only Nelson Mandela.

By "political" prisoners is meant people convicted of crimes motivated by political goals, and those held without trial under emergency regulations. 
(2) Draw up an agenda for a national convention in which -

(a) all leaders including African National Congress are invited,

(b) only Bishop Tutu, or

(c) all but Nelson Mandela.

(3) Main Neo-Apartheid, a weaker form of the classical apartheid. Remove (a) apartheid in buses, etc.

(b) on beaches,

(c) other forms of discrimination.

(4) Revoke the newly instituted Regional Councils to -

(a) give local governments more autonomy,

(b) accept urban migration and develop an urbanisation policy, and

(c) abolish forced removals and family breakups.

(5) Improve the conditions of Blacks.

(a) Decentralize industries to Black homelands,

(b) promote Black education,

(c) allocate more budget money to Blacks.

(6) Make a declaration to the effect that citizenship and voting rights in a unitary state will be granted -
(a) within one year,
(b) in one to two years,
(c) in a specified time period greater than two years.

\subsubsection{Black concessions}

(1) Assist in decreasing Western pressure: Persuade the US -
(a) to remove Western trade barriers,
(b) to lift military sanctions,
(c) against disinvestment,
(d) to abandon Sullivan principles.

(2) "Abandon violence" commitments by -
(a) Nelson Mandela,
(b) all leaders,
(c) ANC. 
(3) Stop -
(a) all rent and business boycotts,
(b) general strikes,
(c) boycotts by students,
(d) strikes by trade unions.

(4) Protect -
(a) White political rights,
(b) investments, and
(c) agree to peaceful transition of power.

(5) Agree to power-sharing
(a) immediately,
(b) gradually.

(6) Cooperate with the White government for economic growth.

The White government would benefit if one or more of the following criteria were satisfied:
(a) the White community is appeased,
(b) the Whites maintain political rights,
(c) the economy improves,
(d) the White government gains sympathy from the Western world,
(e) the threat of retaliation against the Whites by the Blacks is decreased, and
(f) the White government creates an acceptable policy for granting Blacks the franchise in a unitary state.

While some dimensions like "appease Whites", "gain sympathy", "improve economy" were further subdivided, others led straight to the leaf nodes consisting of the list of Black concessions. Comparative judgements were made at each level. The judgements for Level 1 in the previous hierarchy are shown in the matrix below. 


\subsection{EXHIBIT 2}

The hierarchy constructed for the White government's estimate of its benefits from

Black concessions was as follows:

GOAL

ESTIMATING WIITTE GOVERNHENT'S BENEFITS

FROH BLACK CONCESSIONS

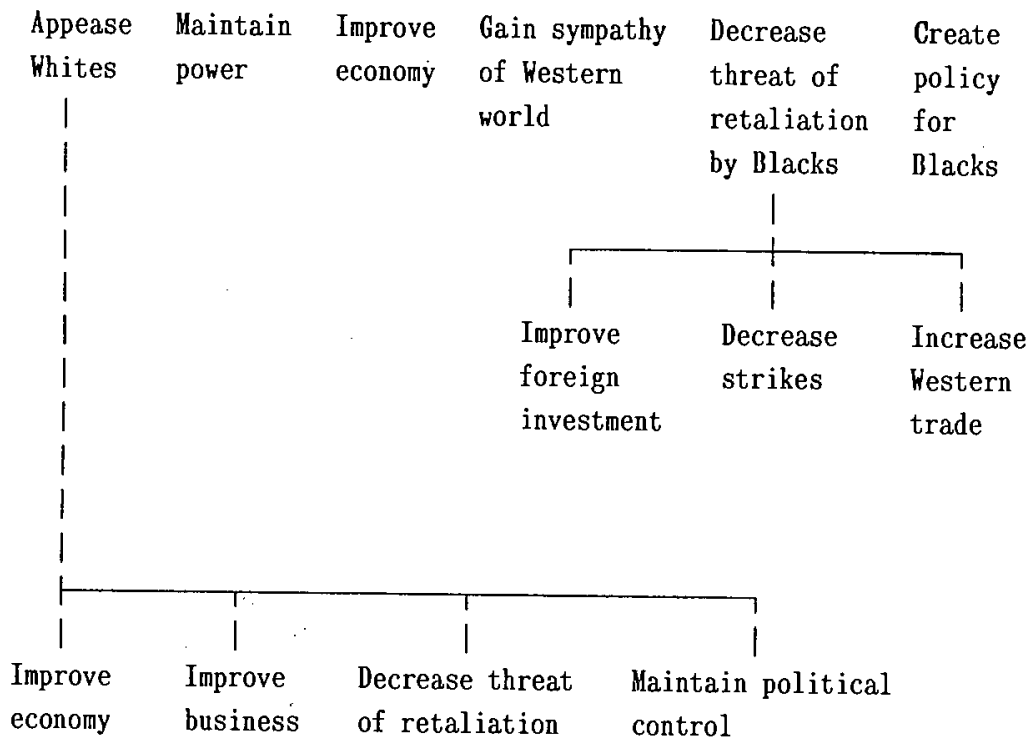

Black concessions

$1 \quad 2$

34

5

6

Assist Decr. Abandon Stop Boycotts Protect White Power Cooperate for Pressures Violence and Strikes Rights and Sharing Economic Growth Investments 


\subsection{THE AHP}

There are three principles which one can recognize in problem solving. They are the principles of decomposition, comparative judgements, and synthesis of priorities.

The decomposition principle calls for structuring the hierarchy to capture the basic elements of the problem. An effective way to do this is first to work downward from the focus in the top level to criteria bearing on the focus in the second level, followed by subcriteria in the third level, and so on, from the more general (and sometimes uncertain) to the more particular and definite. One can then start at the bottom, identifying alternatives for that level and attributes under which they should be compared which fall, in the next level up. Then one finds an intermediate set of higher criteria that can both be decomposed into these attributes and are themselves decompositions of the higher level criteria or subcriteria identified in the downward process. In this way, one can link the focus of the hierarchy to its bottom level in a sequence of appropriate intermediate levels. The levels of a decomposition are an essential part of measurement, and, hence, adjacent ones should generally not be too disparate, that is they do not differ by more than a "qualitative" order of magnitude. In general, the bottom level of the hierarchy contains the resources to be allocated, or the alternatives from which the choice is to be made.

The principle of comparative judgements calls for setting up a matrix to carry out pairwise comparisons of the relative importance of the elements in the second level with respect to the overall objective (or focus) of the first level. In the case where no scale of measurement exists, this is a judgement made by the individual or group solving the problem. The scale for entering judgements is given in Table 1. Additional comparison matrices are used to compare the elements of the third level with respect to the appropriate parents in the second, and so on down the hierarchy. The process could be started at the bottom level and move upward. An entry of each matrix belongs to a fundamental scale employed in the comparisons. These entries are used to generate a derived ratio scale. The next step deals with the composition of the derived ratio scales.

The synthesis of priorities principle is now applied. Priorities are synthesized from the second level down by multiplying local priorities by the priority of their corresponding criterion in the level above, and adding them for each element in a level according to the criteria it affects. (The second level elements are each multiplied by unity, the weight of the single top level goal.) This gives the composite or global priority of that element 
TABLE 1

TIIE FUNDAMENTAL SCALE

\section{Intensity of Importance on an Absolute Scale}

1

3

5

7

9

$2,4,6,8$

Reciprocals

Rationals

\section{Definition}

Equal importance.

Moderate importance of one over another.

Essential or strong importance.

Very strong importance.

Extreme importance.

Intermediate values between the two adjacent judgements.

If activity $i$ has one of the above numbers assigned to it when compared with activity $j$, then $j$ has the reciprocal value when compared with i.

Ratios arising from the scale.

\section{Explanation}

Two activities contribute equally to the objective.

Experience and judgement strongly favor one activity over another.

Experience and judgement strongly favor one activity over another.

An activity is strongly favore and its dominance demonstrated in practice.

The evidence favoring one activity over another is of the highest possible order of affirmation.

When compromise is needed.
If consistency were to be forced by obtaining $\mathbf{n}$ numerical values to span the matrix.

When the elements being compared are closer together than indicated by the scale, one can use the scale $1.1,1.2, \ldots, 1.9$. If still finer, one can use the appropriate percentage refinement. 
which is then used to weight the local priorities of elements in the level below compared by it as criterion, and so on to the bottom level.

The AHP contains an intrinsic measure of inconsistency for each matrix and for the whole hierarchy. Knowledge of inconsistency enables one to determine those judgements which need reassessment. When a group uses the AHP, their judgements .can be combined after discussion by applying the geometric mean to the judgements which derives from the requirement that the collective judgement itself must satisfy the reciprocal property.

The AHP can be applied to set priorities on the criteria and subcriteria of the hierarchy. The alternatives may be evaluated by paired comparisons (relative measurement). When there are many alternatives, and neither their number nor their kind affects the importance of the criteria, they can be absolutely measured or scored on each criterion according to merit or degree to which they meet the standards.

Many decision problems involve dependence of criteria on alternatives and of higher order criteria on lower order ones; also alternatives may depend on other alternatives. A particularly useful generalization of the theory to deal with such dependence situations has been formalized within a network system with feedback of which a hierarchy is a special case.

Let us now describe in greater detail the comparison process and how it is used.

The smaller of two elements being compared is considered to be the unit; the larger one is assessed as so many times larger, using intensity of feeling as the measure and translating this to a numerical value. We can show that the derived scale from the comparisons is insensitive to small changes (corresponding to uncertainty between two neighbouring intensities) in the values of the paired comparisons.

If exact numbers for the comparisons are known and their ratios are used, the derived scale gives back their relative values. However, even when exact numbers are available, the values of these numbers ordinarily need to be compared (by interpreting their relative importance) and used instead of the numbers themselves. For example, to a family of modest income a US $\$ 20000$ car may be much more expensive than a US $\$ 10000 \mathrm{car}$; but to a military budget planner these costs may be about equal. For further detail on the scale see reference ${ }^{12}$ ) below. 
The scaie is used to enter numerical judgements in a matrix for the strength of dominance of a criterion in the column on the left over each of the same criteria listed in the row on top. A reciprocal is used in case the criterion on top dominates the criterion on the left. The reciprocals are automatically entered in the transpose position. The relative weights are obtained by deriving the principal eigenvector of the matrix, which is the only way to capture the relative rank of the criteria when inconsistency is allowed. The principal eigenvalue is used to measure the amount of inconsistency which should not far exceed $10 \%$. The computer program Expert Choice enables one to find out where the most inconsistent judgements are and improve them, if desired.

\subsubsection{Matrix of comparative judgement for level I}

\section{AW MP EC GS DR BP Weight}

\begin{tabular}{|c|c|c|c|c|c|c|c|c|}
\hline $\begin{array}{l}\text { Appease White } \\
\text { community (AW) }\end{array}$ & 1 & 1 & $1 / 2$ & 5 & 6 & 4 & 3 & .291 \\
\hline $\begin{array}{l}\text { Maintain power } \\
\text { (MP) }\end{array}$ & 1 & 2 & 1 & 4 & 5 & 5 & 6 & .377 \\
\hline $\begin{array}{l}\text { Improve economy } \\
\text { (EC) }\end{array}$ & 1 & $1 / 5$ & $1 / 4$ & 1 & 7 & 4 & 3 & .155 \\
\hline $\begin{array}{l}\text { Gain sympathy } \\
\text { (GS) }\end{array}$ & 1 & $1 / 6$ & $1 / 5$ & $1 / 7$ & 1 & $1 / 6$ & $1 / 3$ & .032 \\
\hline $\begin{array}{l}\text { Decrease retaliation } \\
\text { (DR) }\end{array}$ & 1 & $1 / 4$ & $1 / 5$ & $1 / 4$ & 6 & 1 & 1 & .078 \\
\hline $\begin{array}{l}\text { Formulate acceptable } \\
\text { Black policy (BP) }\end{array}$ & 1 & $1 / 3$ & $1 / 6$ & $1 / 3$ & 3 & 1 & 1 & .067 \\
\hline
\end{tabular}

Inconsistency $=11.6 \%$

As a motivation for the relative weights derived from the above matrix of comparative judgements expressing our evaluation of Government goals, one may surmise that the main objective of the White government is to maintain power. The second most important concern of the White government is to appease that section of the White community whose discontentment has for instance led to the rise of the Afrikaner-led Conservative Party, which poses a threat to the ruling Nationalist Party in certain 
conservative constituencies. Improving the economy was considered to be more important than gaining sympathy because most of the sanctions against South Africa have been ineffective. Gaining sympathy was considered to be less important than decreasing the threat of retaliation because a section of the White community is not willing to consider sharing power with the Blacks, although the stated SA Government policy is democratic rule within the mechanism of power-sharing.

\subsubsection{Results}

Subjective judgements were made at each level to complete the hierarchy. The results were aggregated to calculate the White government's benefits from each of the Black concessions, and are set out in Tables 2 and 3, together with the costs and benefits, both actual and perceived, for each party for both sets of concessions.

Table 2 gives the account from the perspective of the Whites and Table 3 gives the account from the perspective of the Blacks. Columns 3 and 6 in Table 2 show the total White losses and total Black gains from the White government's concessions. Column 3 is the product of Columns 1 and 2 and Column 6 is the product of Columns 4 and 5 . Similarly, in Table 3, Columns 3 and 6 show respectively from the Blacks' perspective the total gain to Whites and the total loss to Blacks from Blacks' concessions.

These estimates of gains and losses are used by each party in deciding whether it should make a concession in return for a concession by the other party. For instance, the total White losses from the White government's concession of "Release only Nelson Mandela" have the value of 1860 (Column 3, Table 2). For convenience the priorities of all alternatives have been multiplied by 100000 . Thus 1860 corresponds to the priority .01860. The White government will agree to make this concession in exchange for any concession by the Blacks which will give the White government gains of greater than 1860. A list of Black concessions satisfying this criterion (from Column 3, Table 3) is shown below in Table 4. But the Blacks will agree to making any of the concessions identified in Table 4 if, and only if, the gain to them from the White concession of "Release only Nelson Mandela" of 561 (Column 6, Table 2) is greater than their loss from making any of the Black concessions. As shown, the Black losses from any of the Black concessions are always greater than 561. The ratios of gains/losses are also calculated by each party and for this particular case are shown in Table 4. As can be seen, while this ratio is always greater than one for the Whites, it is much less than one for the Blacks. Thus the Blacks would not agree to this exchange. 


\section{TABLE 3}

\section{BLACK CONCESSIONS}

1(a) No Trade Barriers

1(b) No Military Sanctions

1(c) No Disinvestment

1(d) No Sullivan Principles

2(a) Mandela Appeal for Non-Violence

2(b) All Leaders Appeal for Non-Violence

2(c) ANC Agrees to Non-Violence

3(a) Stop Boycott of Rent $\&$ Business

3(b) No Strikes

3(c) Stop School Boycotts

3(d) No Threats by Unions

4(a) Protect White Political Rights

4(b) Protect White Investments

4(c) Peaceful Transition

5(a) Agree to Power Sharing

5(b) Gradually Growth

.170

.088

.04

.066

$\begin{array}{llllllll}6 \text { (a) Co- operate for Economic } & .188 & .129 & 24 & 252 & .068 & .215 & 14\end{array}$
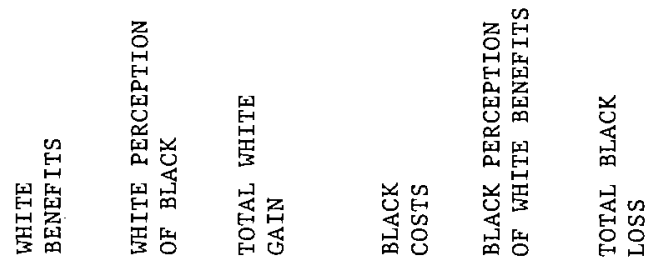

$\begin{array}{llllll}.047 & .097 & 4559 & .124 & .069 & 8556 \\ .020 & .042 & 840 & .053 & .03 & 1590 \\ .117 & .242 & 28314 & .309 & .173 & 53457 \\ .008 & .018 & 144 & .022 & .013 & 286\end{array}$

$\begin{array}{lll}.034 & .029 \quad 986\end{array}$

$.022 \quad .021$

462

.147

24990

.110

.106

11660

$.029 \quad 986$

$.022 \quad .021$

462

.078

6864

.058

.043

2494

$.026 \quad .023 \quad 598$

$\begin{array}{lll}.025 & .022 & 550\end{array}$

$.017 \quad .013$

221

.037

1517

.016

.012

192

$\begin{array}{lll}.027 & .020 & 540\end{array}$

.037

2442

$.044 \quad .016$

704

016

$.009 \quad 144$

$.010 \quad .038$

380

.019

.01

190

$.012 \quad .045$

540

$\begin{array}{rrr}.034 & .017 & 578 \\ .034 & .017 & 578\end{array}$

$\begin{array}{lll}.029 & .007 & 203\end{array}$

$\begin{array}{lll}.029 & .007 & 203\end{array}$ 


\section{TABLE 4}

$\begin{array}{lllll}\begin{array}{l}\text { Black } \\ \text { Concessions }\end{array} & \begin{array}{l}\text { White } \\ \text { gains }\end{array} & \begin{array}{l}\text { Black } \\ \text { losses }\end{array} & \begin{array}{l}\text { White ratio: } \\ \text { gain/loss }\end{array} & \begin{array}{l}\text { Black ratio: } \\ \text { gain/loss }\end{array} \\ & \text { (Col 1) } & \text { (Col 2) } & \text { (Col 1/1860) } & (561 / \text { Col 2) }\end{array}$

1(a). Induce Western world to lift trade barriers against SA:
4559
8556
2.45
0.065

1(c). Pressure US against any form of disinvestment:
28314
53457
15.22
0.01

2(b). All SA leaders appeal for nonviolence:

$\begin{array}{llll}24990 & 11660 & 13.43 & 0.048\end{array}$

3(a). Stop all boycotts:
6864
2494
3.69
0.225

4(a). Agree to White political rights in future:
2442
704
1.31
0.79

6(a). Cooperate for economic growth:

$24252 \quad 14620$

13.03

0.038

The numbers in Columns 1 and 2 of Table 4 are priorities that have been multiplied by 100000 .

This impasse was reached because each party wants its gains to be approximately greater than its losses, yet the ratio of gains/losses is less than one for the Blacks. A mediator is thus needed for reconciliation, otherwise the Blacks could attempt to raise the cost for the Whites through undesirable acts.

\section{THE SOUTH AFRICAN CONFLICT WITH A MEDIATOR}

A mediator evaluates for each party what it says it is giving up and what it is receiving based on its declared values (benefits and costs) and attempts to obtain convergence in a 
way which shows each party that the outcome is fair - that is, that both their ratios are close. He must substitute each party's perception of benefits and costs to the other by what he knows about the other party's values, avoiding exaggerations and distortions.

Black concessions for which the White Government's gain are greater than the loss for their concession: "release only Nelson Mandela".

The objective of the mediator is to ensure that each party's gains/losses ratio is close to or greater than one and that one party does not perceive the other party's ratio to be much greater than its own. Specifically, in the above example the mediator has to devise means of making the gains/losses ratio of the Blacks comparable with that of the White government on at least one Black concession so that the White government can agree to making its concession to release Nelson Mandela. As can be seen from Table 4, the White government's gains/losses ratio is the least and the Black's ratio is greatest for the Black concession of "Protect White political power in the future". The mediator can now try either to decrease the White ratio or to increase the Blacks' ratio. Let us assume that the latter alternative is chosen. One of the ways of achieving this is for the mediator to increase the Black perception of the costs of Whites' concessions to Blacks. This now requires that Blacks change their hierarchy for estimating the Blacks' perception of Whites' costs.

By changing the paired comparison judgements in one of the hierarchies, we observed that the negotiator could convince the Blacks to change their perception of Whites' costs from 0.033 (Column 5, Table 2) to 0.045 for Whites' concession "Release Nelson

... Mandela". This reflects a judgement regarding the flexibility of the Blacks. With this change, the total Black gains increase to 765. The resulting ratios of gains/losses of the Blacks is now 1.36 while it remains 1.31 for the Whites.

As the two ratios are comparable and greater than one, the exchange of the White government's concession to release Nelson Mandela for the Blacks' agreement to protect Whites' political rights in the future would be acceptable to both parties.

The crucial part in the negotiation process is therefore the change in the hierarchy induced by the mediator so that both parties are satisfied.

A list of all sets of concessions with ratios sufficiently close to one for either party were identified in an exhaustive list as the workable ones where the mediator might be able to influence the perceived judgements so that the exchange would become acceptable. 
Some of the acceptable sets are (White concession, Black concession) : (Release all political prisoners, Blacks agree to power-sharing immediately rather than Black rule), (Develop a rational urbanization policy for Blacks, Blacks agree to gradual sharing of political power within two years), and perhaps not as relevant at this stage, (Revoke the newly instituted Regional Councils, all Black leaders in SA appeal for abandoning violence).

After deleting pairs of concessions in which either party's ratio is not "close to" one, a total of 21 acceptable sets surmised by the mediator from the parties' judgements were selected. See Table 5. Because it is assumed that the mediator is unbiased, and therefore equitable concession sets are preferred over non-equitable ones, the concessions were subdivided into two groups depending on whether the gain/loss ratios of both parties were nearly equal and thus fair, or dissimilar. The former were assigned greater weights because the mediator prefers them.

TABLE 5

\section{EqUTTABLE AND FAIR SETTLEMENT OF CONFLICT}

\section{EqUTTARLE}

\begin{tabular}{|c|c|c|c|c|c|}
\hline $\begin{array}{l}\text { Concessions } \\
\text { Gain/Loss/Ratios }\end{array}$ & $\begin{array}{l}(1 \mathrm{a}, 5 \mathrm{~b}) \\
(.85, .98)\end{array}$ & $\begin{array}{l}(1 \mathrm{a}, 5 \mathrm{a}) \\
(.85, .98)\end{array}$ & $\begin{array}{c}(5 b, 3 b) \\
(2.7, .90)\end{array}$ & $\begin{array}{l}(2 c, 5 a) \\
(.80,1.8)\end{array}$ & $\begin{array}{l}(2 c, 5 b) \\
(.80,1.8)\end{array}$ \\
\hline $\begin{array}{l}\text { Concessions } \\
\text { Gain/Loss Ratios }\end{array}$ & $\begin{array}{l}(4 b, 5 a) \\
(.90,1.9)\end{array}$ & $\begin{array}{c}(4 b, 5 b) \\
(.90,1.9)\end{array}$ & $\begin{array}{l}(4 c, 5 a) \\
(.90,1.9)\end{array}$ & $\begin{array}{l}(4 c, 5 b) \\
(.90,1.9)\end{array}$ & $\begin{array}{l}(2 \mathrm{c}, 5 \mathrm{~b}) \\
(.80,1.8)\end{array}$ \\
\hline \multicolumn{6}{|c|}{ INEQUTTABLE } \\
\hline $\begin{array}{l}\text { Concessions } \\
\text { Gain/Loss Ratios }\end{array}$ & $\begin{array}{c}(4 b, 2 c) \\
(1.5,1.1)\end{array}$ & $\begin{array}{l}(4 \mathrm{~b}, 2 \mathrm{a}) \\
(1.5,1.1)\end{array}$ & $\begin{array}{l}(4 c, 2 c) \\
(1.5,1.1)\end{array}$ & $\begin{array}{l}(4 c, 2 a) \\
(1.5,1.1)\end{array}$ & $\begin{array}{l}(4 \mathrm{~b}, 5 \mathrm{a}) \\
(.09,2.5)\end{array}$ \\
\hline $\begin{array}{l}\text { Concessions } \\
\text { Gain/Loss Ratios }\end{array}$ & $\begin{array}{l}(4 \mathrm{c}, 5 \mathrm{a}) \\
(.09,1.9)\end{array}$ & $\begin{array}{c}(6 c, 4 a) \\
(1.18,5.02)\end{array}$ & $\begin{array}{l}(5 \mathrm{c}, 2 \mathrm{~b}) \\
(2.10, .88)\end{array}$ & $\begin{array}{c}(4 a, 2 b) \\
(1.6,1.1)\end{array}$ & $\begin{array}{l}(6 \mathrm{~b}, 6) \\
(.95,3.04)\end{array}$ \\
\hline $\begin{array}{l}\text { Concessions } \\
\text { Gain/Los Ratios }\end{array}$ & $\begin{array}{r}(6 c \\
(3.4\end{array}$ & & & & \\
\hline
\end{tabular}

Note for example that the first pair of numbers $(.85, .98)$ are obtained as follows:

$.85=$ total White gain from Blacks' $5 \mathrm{~b} /$ Total White loss from thites' $1 \mathrm{a}=578$ (From Table 3) $/ 684$ (from Table 2). 
Next, these sets of concessions were categorized as appeasing or minor, moderate, and major, depending on the difficulty of implementing them. For instance, the set of concessions (Release all political prisoners, Blacks agree to power-sharing immediately rather than Black rule) identified above, consists of appeasing concessions by both parties because although perhaps unacceptable to some party, they are easier to implement than others. On the other hand, the set of concessions (Revoke the newly instituted Regional Councils, All leaders in SA appeal for abandoning violence) consists of major concessions. Collections of concessions in the three groups formed the level of alternatives at the bottom of the mediator's decision hierarchy. Nine scenarios for the mediator were constructed. He can focus on short-, medium- or long-range resolution, or on the importance of the concessions. The nine scenarios correspond to the combinations of the above two dimensions and give use to a three by three classification. All 21 sets fall in eaclı of the nine cells, but on ranking them within the cell only the top four concessions were left in that cell and given in Table 6. The ranking involved answering the question: Among the 21 concessions which ones are easier to implement (minor) in the short-, medium- or long-term? Similarly, which are moderately difficult to implement and very difficult to implement in the three time horizons.

TABLE 6

PROCESS OF NEGOTIATION ${ }^{*}$

\begin{tabular}{llll}
\multirow{4}{*}{ Appeasing } & Short-term & Mid-term & Long-term \\
& $(1 \mathrm{a}, 5 \mathrm{a})$ & $(1 \mathrm{a}, 5 \mathrm{a})$ & $(1 \mathrm{a}, 5 \mathrm{a})$ \\
& $(2 \mathrm{c}, 5 \mathrm{a})$ & $(1 \mathrm{a}, 5 \mathrm{~b})$ & $(1 \mathrm{a}, 5 \mathrm{~b})$ \\
& $(1 \mathrm{a}, 5 \mathrm{~b})$ & $(2 \mathrm{c}, 5 \mathrm{a})$ & $(2 \mathrm{c}, 5 \mathrm{~b})$ \\
Moderate & $(2 \mathrm{c}, 5 \mathrm{~b})$ & $(2 \mathrm{c}, 5 \mathrm{~b})$ & $(2 \mathrm{c}, 5 \mathrm{a})$ \\
& $(6 \mathrm{~b}, 6)$ & $(6 \mathrm{~b}, 6)$ & $(6 \mathrm{~b}, 6)$ \\
& $(1 \mathrm{a}, 5 \mathrm{a})$ & $(1 \mathrm{a}, 5 \mathrm{a})$ & $(1 \mathrm{a}, 5 \mathrm{a})$ \\
\multirow{3}{*}{ Major } & $(6 \mathrm{c}, 3 \mathrm{a})$ & $(6 \mathrm{c}, 3 \mathrm{a})$ & $(6 \mathrm{c}, 3 \mathrm{a})$ \\
& $(6 \mathrm{c}, 4 \mathrm{a})$ & $(1 \mathrm{a}, 5 \mathrm{~b})$ & $(1 \mathrm{a}, 5 \mathrm{~b})$ \\
& $(6 \mathrm{~b}, 6)$ & $(6 \mathrm{~b}, 6)$ & $(6 \mathrm{~b}, 6)$ \\
& $(6 \mathrm{c}, 3 \mathrm{a})$ & $(6 \mathrm{c}, 3 \mathrm{a})$ & $(6 \mathrm{c}, 3 \mathrm{a})$ \\
& $(6 \mathrm{c}, 4 \mathrm{a})$ & $(6 \mathrm{c}, 4 \mathrm{a})$ & $(6 \mathrm{c}, 4 \mathrm{a})$ \\
& $(4 \mathrm{c}, 5 \mathrm{a})$ & $(4 \mathrm{a}, 2 \mathrm{~b})$ & $(4 \mathrm{a}, 2 \mathrm{~b})$
\end{tabular}

The numbers and letters in the table correspond to pairs of (White, Blac. concessions that can be offered. See Exhibit 1 given earlier. He may ha erred in assessing the concessions $6 b$ for Whites and $5 b$ for Blacks short-term. It is possible to recompute this table and put greater empha on citizenship in the mid or long terms. 
The sets of concessions which the mediator should strive to exchange, depend upon whether short-term or long-term goals are emphasized. For instance, a focus on short-term goals, with an emphasis on minor concessions from the parties, requires striving to exchange the concession (release all political prisoners, Blacks agree to sharing of-political power immediately rather than insisting on Black rule). On the other hand, a long-term and major concession requires the mediator to strive for the exchange: (Make a declaration of intent to grant some type of voting rights to Blacks after no more than two years, Blacks agree to cooperate for economic growth in the region). Note that South African citizenship has already been extended to South African Blacks (excluding certain categories of independent homeland Blacks). It is of course not a citizenship which includes the right to vote for Parliament at this stage.

\section{CONCLUSION}

The results of the above analysis can be used to propose a series of steps that could be effective in bringing the Blacks and Whites closer together. Because of the intense nature of the conflict characterized by violent actions, coupled with a lack of trust that the White government would institute "real" reform, the immediate concern should perhaps be to decrease hatred and establish trust between Blacks and Whites. This is clearly a short-term goal. Thus, the exchange of the White government's concessions of releasing all political prisoners or inviting all Black political leaders except Nelson Mandela (unless he condemns violence) to a national convention in return for the Blacks' concession agreeing to share political power rather than insisting on Black rule, should be the focus of negotiations. Over the long run, to ensure that the process of reform continues, moderate and major concessions producing results in the near term (mid-term goals) are needed. Therefore the negotiations should focus on the White government agreeing to grant voting rights to the Blacks sometime in the next two to five years, and the Blacks agreeing not to make use of violence and boycotts, and also to work towards the economic growth of the region. Finally, a long-term perspective with major concessions by both parties requires that the White government agree to the previous concessions and stop relocating Blacks to their homelands with Blacks agreeing to negotiate some form of power sharing. In addition to the previous concessions, the Blacks should agree to protect White political rights on a long-term basis.

The proposed solution has been reached by moving along the right diagonal (diagonal from the top left corner) of Table 6 . This need not be the case for other conflicts. For 
instance, if the conflict is moderate wilhout extreme polarization of the partics' interests, perhaps the mid-term goals can be emphasized directly. Or in some conflicts only moderate concessions will achieve even the short-term goals because of an extreme escalation of conflict. Thus, the path to be taken through Table 6 would depend on the nature of the conflict.

Using the above hierarchy, a number of different options are available to the mediator. While the hierarchy identifies the major decision-making parameters for the mediator, his goals and perceptions can be implemented in other parts of the negotiation process. For instance, rather than believing the estimates of gains and losses for the parties as being the true values, an attempt could be made to estimate the "true" value depending on his perceptions of the parties. The hierarchies could thus be constructed, one each for the parties, in which the gains and losses from concessions are modified by the mediator. The mediator now uses his perceptions of gains and losses to evaluate the sets of acceptable concessions. Such modifications depend to a large extent on the specific situation. Other similar kinds of roles for the mediator in the context of other conflicts are under study.

The results of the many-faction analysis for both parties, not shown here, are very different from the above case. A focus on short-term goals, with an emphasis on minor concessions from the parties, requires striving for exchange of the concession (White government inviting all political leaders, and conditionally Nelson Mandela, to a convention, and Blacks agreeing to stop all strikes). On the other hand, long-term and major concessions require the mediator to strive towards getting the Blacks to agree to gradual power-sharing, rather than insisting on Black rule, in return for a number of policy changes already adopted by the Whites including the long standing policy of decentralizing industry.

Still considerable change in attitude and understanding are needed to make negotiation a high priority concern in solving the problem - cooperation instead of confrontation. 


\section{REFERENCES}

1. Nierenberg, G I, Creative Business Negotiating, Hawthorn Books, Inc., New York, 1971.

2. Nierenberg, G I, The Art of Negotiating, Hawthorn Books, Inc., New York, 1968.

3. Ikle, F C, How Nations Negotiate, Frederick A Praeger, New York, 1964.

4. Zartman, I W and M R Berman, The Practical Negotiator, Yale University Press, New Havem, 1982.

5. Mitchell, C R, Peacemaking and the Consultant's Role, Nichols Publishing Co., New York, 1981.

6. Ikle, F C, op cit.

7. Fisher, $\mathrm{R}$ and $\mathrm{W}$ Ury, Getting to Yes: Negotiation Agreement Without Giving In, Penguin Books, New York, 1983.

8. Zartman, $I \mathrm{~W}$ and $\mathrm{M} \mathrm{R}$ Berman, op cit.

9. Axelrod, R, The Evolution of Cooperation, Basic Books, Inc., New York, 1984.

10. Expert Choice software package used in the analysis, Decision Support Software, 1300 Vincent Place, McLean, Virginia, 22101, USA.

11. See: Saaty, T L, The Analytic Hierarchy Process, McGraw-Hill, 1980; Saaty, T L, Decision Making for Leaders, TLS Publications, Pittsburgh, 1986; and Tarbell D S and T L Saaty, "The Conflict in South Africa", Journal of Peace Science, Vol. 4, No. 2: 1980, pp. 151-168.

12. Saaty, T L, The Analytical Hierarchy Process, op cit. Revised with many additions included RWS Publication 4922 Ellsworth Avenue, Pittsburgh, PA 15213, 1988. 